\title{
Corrigendum
}

\section{Corrigendum to “Antibacterial Screening of Gunnera perpensa-Mediated Silver Nanoparticles"}

\author{
Naazlene Patel, Kabange Kasumbwe, Viresh Mohanlall (D, \\ and Londiwe Simphiwe Mbatha
}

\begin{abstract}
Department of Biotechnology and Food Technology, Faculty of Applied Sciences, Durban University of Technology, P.O. Box 1334, Steve Biko Campus, Durban 4001, South Africa

Correspondence should be addressed to Viresh Mohanlall; vireshm@dut.ac.za

Received 26 November 2020; Accepted 26 November 2020; Published 7 December 2020

Copyright ( 92020 Naazlene Patel et al. This is an open access article distributed under the Creative Commons Attribution License, which permits unrestricted use, distribution, and reproduction in any medium, provided the original work is properly cited.
\end{abstract}

In the article titled "Antibacterial Screening of Gunnera perpensa-Mediated Silver Nanoparticles" [1], the author Londiwe Simphiwe Mbatha was omitted from the article in error. This has been corrected as shown in the above author list.

\section{References}

[1] N. Patel, K. Kasumbwe, V. Mohanlall, and L. S. Mbatha, "Antibacterial screening of Gunnera perpensa-mediated silver nanoparticles," Journal of Nanotechnology, vol. 2020, Article ID 4508543, 7 pages, 2020. 